\title{
Do ambulante ao empreendedor: uma etnografia no comércio da comida de rua no
}

\section{Recôncavo da Bahia}

From the street vendor to the entrepreneur: an ethnography in the street food trade in Recôncavo da Bahia

De vendedor ambulante a emprendedor: una etnografía en el comercio callejero de alimentos en Recôncavo da Bahia

Gizane Ribeiro de Santana ORCID: https://orcid.org/0000-0003-2345-5967 Universidade Federal do Recôncavo da Bahia, Brasil E-mail: gizane@ufrb.edu.br

Lígia Amparo-Santos

ORCID: https://orcid.org/0000-0002-6925-6421 Universidade Federal da Bahia, Brasil E-mail: amparo@ufba.br

\begin{abstract}
Resumo
O artigo buscou compreender o processo de transição do ambulante ao empreendedor na comida de rua, a partir de um estudo etnográfico desenvolvido junto aos trabalhadores deste comércio, na cidade de Santo Antônio de Jesus, Recôncavo da Bahia. A etnografia seguiu a linha analítico-interpretativa de Clifford Geertz. A etapa de campo durou sete meses, com uso das técnicas: observação sistemática e participante e entrevistas com ambulantes e informanteschave. Outras fontes alternativas, como reportagens de sites e jornais locais compuseram o estudo. A análise fundamentou-se em teóricos como Ricardo Antunes, para discutir questões que acercam o trabalho informal, o vir-aser empreendedor e a precarização no trabalho ambulante. Verificou-se que a implementação do Programa SAJ Legal, intervenção política que visou reorganizar e reestruturar o comércio de rua na cidade, culminou na "recategorização" dos ambulantes à microempreendedores. Parte destes não reconheciam a "identidade" de MEI, forjada pelo poder público, significados revelados em micro ações, como táticas de resistência e verbalizações dissonantes, na prática do labor. O Programa revelou adotar estratégias baseadas em políticas neoliberais, ao assumir o discurso "empreendedor" para regulação, em detrimento de uma política de proteção social para esses sujeitos. Assim, a formalização do ambulante à MEI representou menos uma política resolutiva, do que repercutiu como parâmetro de higienização social e estratégia econômica. Essas manifestações denotaram que a corrosão dos direitos do trabalhador, encoberta sob o véu do discurso empresarial, atendem, prioritariamente, ao mercado financeiro e representam o contingenciamento de novas formas de exclusão e precarização dos vínculos de trabalho.
\end{abstract}

Palavras-chave: Alimentos de rua; Comércio informal; Ambulante; Empreendedor; Etnografia.

\begin{abstract}
The article sought to understand the process of transition from street vendor to entrepreneur in street food, based on an ethnographic study carried out with workers in this trade, in the city of Santo Antônio de Jesus, Recôncavo da Bahia. Ethnography followed the analytical-interpretive line of Clifford Geertz. The field stage lasted seven months, using the techniques: systematic and participant observation and interviews with street vendors and key informants. Other alternative sources, such as reports from websites and local newspapers, made up the study. The analysis was based on theorists such as Ricardo Antunes, to discuss issues surrounding informal work, becoming an entrepreneur and the precariousness of street work. It was found that the implementation of the SAJ Legal Program, a political intervention aimed at reorganizing and restructuring street commerce in the city, culminated in the "recategorization" of street vendors to microentrepreneurs. Part of these did not recognize the "identity" of MEI, forged by the public power, meanings revealed in micro actions, such as resistance tactics and dissonant verbalizations, in the practice of labor. The Program revealed to adopt strategies based on neoliberal policies, when assuming the "entrepreneurial" discourse for regulation, to the detriment of a social protection policy for these subjects. Thus, the formalization of the street vendor to the MEI represented less of a resolutive policy than it had as a parameter of social hygiene and economic strategy. These manifestations showed that the corrosion of workers' rights, hidden under the veil of business discourse, primarily serve the financial market and represent the contingency of new forms of exclusion and precarious employment relationships.
\end{abstract}

Keywords: Street food; Informal trade; Walking; Entrepreneur; Ethnography. 


\begin{abstract}
Resumen
El artículo buscó comprender el proceso de transición de vendedor ambulante a emprendedor en la comida callejera, a partir de un estudio etnográfico realizado con trabajadores de este oficio, en la ciudad de Santo Antônio de Jesus, Recôncavo da Bahia. La etnografía siguió la línea analítico-interpretativa de Clifford Geertz. La etapa de campo duró siete meses, utilizando las técnicas: observación sistemática y participante y entrevistas con vendedores ambulantes e informantes clave. Otras fuentes alternativas, como informes de sitios web y periódicos locales, conformaron el estudio. El análisis se basó en teóricos como Ricardo Antunes, para discutir temas relacionados con el trabajo informal, el emprendedor y la precariedad del trabajo de calle. Se encontró que la implementación del Programa Legal SAJ, una intervención política que tuvo como objetivo reorganizar y reestructurar el comercio callejero en la ciudad, culminó con la "recategorización" de los vendedores ambulantes a microempresarios. Parte de ellos no reconoció la "identidad" del MEI, forjada por el poder público, significados revelados en micro acciones, como tácticas de resistencia y verbalizaciones disonantes, en la práctica del trabajo. El Programa reveló adoptar estrategias basadas en políticas neoliberales, al asumir el discurso "empresarial" para la regulación, en detrimento de una política de protección social para estos sujetos. Así, la formalización del vendedor ambulante al MEI representó una política menos resolutiva, que repercutió como parámetro de higiene social y estrategia económica. Estas manifestaciones mostraron que la corrosión de los derechos de los trabajadores, escondidos bajo el velo del discurso empresarial, sirven principalmente al mercado financiero y representan la contingencia de nuevas formas de exclusión y precarias relaciones laborales.
\end{abstract}

Palabras clave: Comida callejera; Comercio informal; Vendedor Ambulante; Empresario; Etnografía.

\title{
1. Introdução
}

O estudo buscou compreender o processo de transição do ambulante ao empreendedor na comida de rua, a partir de um estudo etnográfico desenvolvido junto aos trabalhadores deste comércio, na cidade de Santo Antônio de Jesus, Recôncavo da Bahia.

Ressalta-se que a expressão comida de rua, agrega um conjunto de produtos caracterizados como 'comida', que foram assim incorporados, conforme a definição acordada pela FAO, que veio para "descrever uma ampla gama de alimentos e bebidas prontos-para-comer vendidos e por vezes preparados em espaços públicos, nomeadamente rua" (Winarno, 1986, p. 1).

A leitura que se têm da comida de rua na Modernidade Ocidental, está fortemente conectada ao conceito de atividade ambulante, uma denominação usual ao senso comum, que simboliza, de maneira elementar, a propriedade de deslocamento atrelada ao tipo de comércio. Todavia, essa caracterização, não representa, a rigor, os rumos que a prática vem tomando, em termos de configuração espacial nas cidades. Os trabalhadores desse ramo, absorvidos pela dinâmica urbana, muitas vezes veem-se inseridos em um sistema de regulação, padronização e remodelamento, praticado por representantes dos poderes públicos, que incluem intervenções como a formatação e fixação de pontos para venda da comida (Anjaria, 2016; Naik, 2013).

Destaca-se que, embora o comércio ambulante compunha parte integrante das economias urbanas, representando um fenômeno mundial de crescimento rápido, os trabalhadores que executam essa atividade estão, por muito tempo, negligenciados e invisibilizados (Chen, 2012; Maia, 2015; Winarno, 1986).

Essa tendência de marginalização repercute em conformidade ao discurso da globalização e ressoa do próprio capitalismo. Nessa ótica, a desregulamentação financeira e do mundo do trabalho; com a flexibilização da produção, as terceirizações e a intensiva mecanização, resultou na diminuição evolutiva dos postos de trabalho e sua precarização, contribuindo para que, parcela da população, não fosse mais assimilável pela economia formal, restando como desnecessária, ou excluída (Paula Jr, 2005). Por conseguinte, esses trabalhadores excluídos recompunham-se na sociedade capitalista, por meio de alternativas paralelas de adentrar e sobreviver ao sistema, configurando, grosso modo, grande parte da economia informal.

É nessa perspectiva que o mercado da comida de rua, como parte integrante de uma aldeia capitalista global, caracteriza-se, majoritariamente, por integrar um setor informal de atividades econômicas. Esse mercado tem como características a capacidade ímpar de recriar-se e reestruturar-se diante das pressões do espaço, tempo e das diferentes formas de comensalidades e sociabilidades, impostas pelas transformações humanas. 
Estudos que trataram o tema da comida de rua (Anjaria, 2016; Solomon, 2016; Etzold, 2014; Issacs, 2014), revelaram que, a notória propriedade recriadora investida nesse comércio, se deve, entre outros fatores, ao fluxo contínuo de agentes materiais e imateriais, que participam da sua composição, nos diferentes lugares em que se instala e perpetua. Tais análises demarcaram ainda que, desse comércio, despontam lutas constantes para driblar as desigualdades estruturais, sendo diretamente afetado por forças governamentais e privadas, que lideram a economia, e, por concepções ideológicas adstritas a um padrão de estética urbana imperante.

Outrossim, em suas vicissitudes, o comércio praticado em vias públicas intervém na urbe, ao caracterizar-se elemento essencial para conformação de espaços e desempenhar um papel significativo no cotidiano da cidade (Maia, 2015). A autora destaca que, a economia informal está cada vez mais presente e complexa, no que configura a produção regular de riquezas e serviços.

Essa economia da informalidade, na dinâmica contemporânea, ao que parece, vem passando por um processo de mutação, para ressignificar-se no discurso da economia do "empreendedorismo autônomo". É uma estratégia política de cunho positivista, que ressoa demarcada pelo crescente incurso neoliberal, como alternativa de solucionar ou enquadrar os ambulantes desse comércio, que materializam um dilema social secular.

\subsection{Tateando informalidade e empreendedorismo}

No domínio econômico informal, que compreende um conjunto de atividades muito heterogêneas, inserem-se distintos agentes, como as microempresas, os trabalhadores autônomos, os empregados sem carteira de trabalho assinada, os pequenos produtores, a economia subterrânea e submersa etc. (Durães, 2002). Embora incorporado à economia, o ambiente regulatório e de governança, geralmente, negligenciam categorias inteiras da informalidade. Essa 'desregulamentação', ou a incidência de sistemas regulamentares que destoam dos contextos aplicados, podem ser tão onerosas, quanto o seu excesso.

Em todo o mundo, poucos países adotaram uma política coerente em relação ao comércio de rua, a maioria das cidades atribuiu o "manuseio" dos vendedores de rua para os departamentos - como a polícia - que lida com a lei e a ordem (Bhowmik, 2004; Chen, 2012). Assim, os trabalhadores da comida de rua estão continuamente absorvidos por uma lógica dicotômica, que rotula seu trabalho, como na relação entre legalidade e a ilegalidade.

Telles (2009) afirmou que há "porosidade" tanto entre o formal e o informal, quanto entre o legal e ilegal, como uma espécie de "economia política dos ilegalismos urbanos". Segundo a autora, não há diferenciação entre o legal e o ilegal, o lícito e o ilícito, o formal e o informal, mas o entendimento de suas correlações "é uma questão central nos modos de funcionamento do capitalismo contemporâneo" (Telles, 2009 como citado em Raslan, 2019, p. 263).

Por sua contribuição inquestionável na economia, o advento da ressignificação do ambulante à empreendedor autônomo, desponta como uma alternativa que enseja transformar esse contingente ativo de geração de capital, que sempre figurou excluído, em agentes econômicos "legalizados". Essa tendência parece repercutir-se mundialmente, no empenho dos governos para requalificar e registrar tais comerciantes e apontam, sobretudo, para uma estratégia de regulamentação do montante financeiro oriundo dessa atividade, que pode traduzir-se ainda enquanto possibilidade de engolfamento desse mercado, em um regime formalizado.

Nesse ínterim, as esferas do poder urbano que investem na possibilidade de mudança desse domínio, com vislumbre na sua extinção, acabam por reafirmar um suposto papel do comércio informal, como instância capitalista transitória. Entretanto, sua participação na manutenção desse sistema, constitui tese instituída, devido ao fato de que, a atividade se caracteriza como fenômeno recalcitrante nas sociedades.

Sobre essa transitividade intrincada, Greenspan (2018) argumentou que o informal não é simplesmente um fenômeno temporário, e que a concepção evolucionária de crescimento econômico, em que um mercado obscuro "atrasado" progride para 
uma esfera formal "avançada", mascara uma luta profunda. Em Singapura, por exemplo, a visão do vendedor de rua como empreendedor foi bastante romantizada, tornando-o uma figura histórica, que está sendo educada nesse modelo, bem como seu público consumidor. O governo criou até uma nomenclatura própria para categoria "hawkerpreneur" (Tarulevicz, 2018).

A geógrafa Ananya Roy adverte sobre os riscos dessa romantização da "economia do empreendedorismo e da informalidade dinâmica porque, segundo ela, essas são "estratégias de improvisação concebidas sob condições de privação e vulnerabilidade" (Roy, 2011 como citado em Anjaria, 2016, p. 20).

Diante do exposto, apreende-se que as vivências empreendedoras nas ruas, tendem a evocar diferentes acepções a partir dos lugares em que se acomodam, tanto pelos agentes diretamente afetados, como os ambulantes, quanto pelos pretensos promotores da mudança, poder público e/ou privado. Portanto, compreender cada território socio econômico e cultural, no qual essa estratégia "empreendedorizante" se estabelece, configura uma instituição pungente, que pode contribuir para minimizar implicações perversas dessa proposição.

No tocante a definição elucubrada por Baron e Shane (2007), o empreendedorismo é visto, como uma atividade executada por indivíduos específicos, envolvendo ações chaves (identificação de uma oportunidade - potencialmente valiosa no sentido prático e que produza lucros sustentáveis), e atividades ligadas à exploração e o desenvolvimento real de uma oportunidade.

Em países latino americanos, como Brasil, o discurso do empreendedorismo na comida de rua está fortemente atrelado ao conceito de inovação no comércio, com o advento do food truck. Matzembacher et al. (2019) descreveram que, tais empresas, constituíam, em sua maioria, um modelo de administração familiar, sob supervisão de um chef profissional e despontaram no "mercado" da comida urbana em ascensão global.

No cenário brasileiro ressalva-se que, embora o food truck se destaque na literatura pertinente ao tema, como representativo no processo de constituição da lógica empreendedora na comida de rua, uma fração desse comércio, representada pelas baianas do acarajé, por exemplo, que não se enquadram na ótica do food truck, já demonstravam tendências empreendedoras e práticas inovadoras. Esses atributos se revelam, sobretudo, no desenvolvimento de táticas comerciais, e resguardam ainda, o modelo de produção familiar replicado pelo food truck, que persiste, perpetrado historicamente.

Outrossim, o empreendedorismo na comida de rua brasileira ganha corpo por meio da execução de um modelo político regulamentar, que atrela ao comerciante desse segmento, uma vez inserido na estratégia de formalização, a identidade do Microempreendedor Individual (MEI).

Demarca-se que a definição política de MEI no Brasil, contempla um empresário com faturamento bruto de, no máximo, $\mathrm{R} \$ 81$ mil ao ano. Além disso, inclui que, o MEI pode ter um empregado contratado e deve atuar em uma das mais de 490 atividades permitidas para o segmento (Portal Sebrae, 2019). Convém demarcar que, embora a categoria de MEI incorpore àqueles com rendimento anual considerado pequeno, em conjunto, esse setor do trabalho representa uma grande fatia econômica do produto interno bruto do país.

O MEI instituiu-se atividade formalizada, no segundo mandato do partido dos trabalhadores, sob gerência do presidente, Luiz Inácio Lula da Silva, com a Lei Complementar n. 128/2008 e suas atualizações, cujo principal objetivo era "retirar da informalidade milhões de empreendedores" (Portal Sebrae, 2019). Naquele período, marcou-se o fortalecimento do papel do Serviço Brasileiro de Apoio às Micro e Pequenas Empresas (Sebrae), como instituição pública que gerenciava e promovia os trâmites para qualificar e executar o cadastro desses trabalhadores.

Ressalta-se que as atividades permitidas aos microempreendedores são aquelas determinadas pelo Comitê Gestor do Simples Nacional, Resolução n. 140/2018, sendo que, no âmbito da comida de rua, a ocupação indicativa do MEI, para maioria, é a de 'vendedor ambulante de produtos alimentícios independente'.

Dessas elucubrações, que culminam na referência brasileira e suas delimitações acerca do empreendedorismo no 
comércio da comida de rua, demarca-se que a análise desse fenômeno, com foco no ambulante da comida, configura agência pouco explorada pelas publicações cientificas que tratam o tema no Brasil e, ademais, na América Latina, o que abalizou a originalidade desse estudo.

\section{O Território e a Abordagem Metodológica da Pesquisa}

A comida de rua demarca a atividade comercial brasileira, com seu empreendimento simples/artesanal, que evoluiu em sincronia com mudanças ambientais e tecnológicas, e delas se apropriou, em releituras ou inovações criativas pessoais. Essas multiplicaram-se nas esferas urbanas, entre milhares de adeptos, por vocação ou necessidade, na medida em que provia sustento em tempos de crise e escassez alimentar.

Ferreira-Filho (1999) rememora que, nas ruas das vilas coloniais brasileiras, as primeiras escravas passaram a comercializar a comida, como ambulantes, para obter lucro e repassá-los aos seus senhores, sendo por isso denominadas 'ganhadeiras'. As astúcias dessas engenhosas trabalhadoras, resultaram na composição de comidas acessíveis, de sabores e fragrâncias singulares, que, aromatizando a vida naqueles cenários bucólicos, proporcionaram a emergência de figuras folclóricas identitárias, como as baianas do acarajé, que preencheram as ruas da Bahia.

É nessa localidade, que o estudo se estabeleceu, como um dos produtos de uma tese de doutorado, desenvolvida em Santo Antônio de Jesus, território do Recôncavo da Bahia, este, por sua vez, considerado um dos nascedouros do comércio da comida nas ruas brasileiras. Nesta cidade, ocorreu uma estratégia de intervenção, a partir da implantação de um Programa de reestruturação urbana, que culminou na regulamentação e registro dos ambulantes da comida de rua, que passaram a ser categorizados como MEI.

A presente pesquisa, se desenvolveu, portanto, com vistas a compreender esse processo a partir da experiência dos ambulantes/MEI, por meio de um estudo de natureza qualitativa (Pereira et al., 2018), que elegeu a abordagem etnográfica como metodologia para investigação. Nesse escopo, com vistas a capturar as informações em campo, procedeu-se a aplicação das técnicas: entrevistas, observações sistemática e participante, que seguiram a linha analítico-interpretativa, proposta por Geertz (2008).

$\mathrm{Na}$ etapa da observação sistemática, realizou-se visitas aos bairros comerciais e procedeu-se um mapeamento dos locais de venda, possibilitando a aproximação com ambulantes e o ingresso em campo. As investigações in loco, ocorreram nas circunscrições do Centro Comercial, na Praça Padre Mateus, e duraram sete meses, entre agosto de 2018 e fevereiro de 2019. O estudo foi aprovado pelo Comitê de Ética em Pesquisa da Universidade Federal do Recôncavo da Bahia (UFRB)

Constituíram participantes da pesquisa, ambulantes, proprietários de carrinhos e seus subempregados, que participassem da elaboração e venda da comida de rua. Ademais, foram entrevistados informantes chaves, como representantes de poderes públicos municipais e instituições locais. Esses assentiram em colaborar, mediante assinatura do Termo de Consentimento Livre e Esclarecido e suas identidades foram preservadas neste artigo, por meio do uso de pseudônimos.

A descrição do fenômeno partiu de uma confluência de narrativas dos agentes e das observações da pesquisadora que, em campo, experienciou vivências e interlocuções verbais, como entrevistas não estruturadas, com ambulantes e outros agentes que compunham o contexto. As informações acolhidas foram descritas em diário de campo e gravadas em smartphone. Outras fontes de informações documentais e jornalísticas (sites, blogs, jornais locais), também compuseram material empírico para pesquisa.

A saída do campo se deu, conforme saturação empírica das informações, que, após transcritas, foram categorizadas e interpretadas, constituindo o corpus analítico da pesquisa, que resultou na descrição etnográfica.

$\mathrm{Na}$ etapa de análise, as gravações foram alvo do processo de escuta e reescuta, no qual se adotou uma atitude de "atenção flutuante" (Kaufmann, 2018), que seguiu múltiplas pistas para interpretação do fenômeno. Posteriormente, procedeu- 
se a transcrição dos eventos, cenas e diálogos, gestualidades e outros signos não verbais, que circundavam o objeto da análise. Essa transcrição, em conjunto com as anotações do diário, já integrava em si, os germes do método interpretativo-analítico (Bourdieu, 2012).

As vivências e significados foram submetidos a um processo analítico dialético, no qual as tessituras entre observações e a análise das situações comunicativas, fizeram emergir categorias analíticas, como o fenômeno do vir-a-ser empreendedor na comida de rua, pleno de contradições, que se deu a partir da intervenção municipal com os ambulantes em SAJ.

Tal incursão, focalizada neste artigo, foi interpretada e dialogada a partir da obra de Ricardo Antunes (2018) e escritos de outros autores, reunidos por Antunes (2019), no livro "Riqueza e miséria do trabalho no Brasil IV: trabalho digital, autogestão e expropriação da vida". As análises constituídas a partir do incurso etnográfico nesse microcosmo social do mundo do trabalho, adquiriram contornos teóricos, materializados na escrita cientifica que aqui se apresenta.

Posto isso, nos tópicos seguintes abordar-se-á aspectos que emergiram da incursão etnográfica na comida de rua em SAJ, que desvelou um contexto do comércio, dos ambulantes e da implementação do Programa SAJ Legal, este, por seu turno, figurou como estratégia plena de contradições para os trabalhadores, ressoando nas micro ações de resistências, dissonâncias e na constituição de laços frágeis, elementos do vir-a-ser empreendedor na comida de rua.

\section{Resultados e Discussão}

\subsection{Incursão etnográfica na comida de rua em SAJ: a cidade, os ambulantes e a implementação do programa SAJ Legal}

SAJ é reconhecida como capital do comércio varejista do Recôncavo, por abrigar um expressivo número de atividades e pequenos mercados, que alimentam uma economia local e suprem as necessidades de municípios e regiões circunvizinhas. Embora apresente população média de cem mil habitantes (Instituto Brasileiro de Geografia e Estatística, 2018), o fluxo de transeuntes intermunicipais e/ou interestaduais no cotidiano da urbe é intenso. Esse contingente popular, representa uma movimentação financeira ampla, especialmente no setor de serviços, que reúne segmentos formais e informais do comércio.

Nesse interim, emerge o comércio da comida de rua local, visto como atividade informalizada, ou pelo menos assim o foi, até a implantação do Programa SAJ Legal, um instrumento de governança urbana, que introduziu um movimento de reestruturação no comércio de rua e promoveu a higienização de espaços públicos. Demarca-se que o SAJ Legal foi gestado por um partido político que concorreu ao eleições municipais, o Programa constituiu assim promessa de campanha política, cujo candidato à Prefeito foi eleito.

Com a aparente morosidade na implantação da promessa de campanha, convém ressaltar fatos históricos, que forneceram elementos para a execução obrigatória do Programa, por meio de um processo impositivo judicial. O acúmulo de queixas sobre o ambiente do Centro Comercial, por exemplo, que, em seu cerne, abriga a Praça Padre Mateus, lugar preenchido por ambulantes da comida e por moradores de rua, entes incômodos que traduziam um caos urbano, conforme as descrições dos cidadãos e comerciantes lojistas, nas redes midiáticas locais.

Essas queixas centravam-se, especialmente em argumentos como a invasão da criminalidade e a suposta ocorrência de surtos de toxinfecção alimentar na cidade, como narrado na entrevista com Promotor do Ministério Público da Região.

Há uns anos recebi representações da Associação Comercial e outros Órgãos locais, referente ao problema dos ambulantes na cidade, que não tinham cadastro, nem regulamentação e provocavam uma série de inconvenientes. Nós abrimos um inquérito e fomos apurar. Verificamos a necessidade de haver regulamentação no setor, uma organização para o benefício deles mesmos. Então, ingressamos com uma ação civil pública, pedindo ao Judiciário que determinasse ao município a organização do setor. Então a juíza concedeu liminar para que a Prefeitura organizasse o setor. No primeiro momento, a Prefeitura recorreu, houve a suspensão da liminar pelo Ministério da Justiça, mas a Prefeitura resolveu cumprir a decisão, espontaneamente, e iniciou o SAJ Legal (Promotor, janeiro, 2019). 
Infere-se da narrativa, que a condição de ser ambulante da comida em SAJ, estava relacionada com um tipo de atividade marginal, conotação que mesclava componentes de natureza ilícita. Esse comércio era visto como criminalizado, principalmente por afetar a saúde e promover o caos, argumentos que iam de encontro aos ideais de um ambiente moderno e ordeiro, ensejado por moradores e empresários lojistas da região.

Desse modo, o Poder Judiciário local, alinhado ao discurso econômico e político, sucumbiu as manifestações, atuando no sentido de forçar um reordenamento citadino e "formatar" ambulantes, enquadrando seu comércio no modelo ideal. Contudo, o vir-a-ser formalizado, não implicava em um discurso de proteção social para os trabalhadores, pelo contrário, revelava-os sujeitos excluídos, como se não constituíssem cidadãos plenos de direitos e participativos na dinâmica citadina.

Santana \& Amparo-Santos (2021) reiteraram que "como consequência de uma postura excludente a nova ordem Moderna, o comércio da comida de rua, ocupou um espaço de refugo social, por conseguinte, olhares, predominantemente discriminatórios, voltaram-se para os trabalhadores dessa comida, imersos na banalidade da rua". Anjaria (2016) reporta que os ambulantes da comida de rua são frequentemente descritos por ativistas cívicos, funcionários municipais e jornalistas como "incômodo"; e são vistos como representantes do caos nas ruas e causa do notório congestionamento da cidade. Para outros, eles representam uma alegação imerecida dos pobres nos espaços públicos.

Assim, a implementação do SAJ Legal constituiu uma resposta em caráter de urgência as liminares, que o Ministério Público impetrou à Prefeitura. A narrativa da Secretária de Infraestrutura local, descreve-o como um Programa que visou a reorganização de inúmeras atividades exercidas no município.

É uma iniciativa das secretarias envolvidas, assim como a Vigilância Sanitária Municipal, para que o mercado informal de comercialização de alimentos seja enquadrado nas normativas exigidas pelo Programa. As inspeções foram feitas no intuito de regulamentar comerciantes nos termos de padronização, condições de equipamentos, segurança e higiene, 'estamos sendo acompanhados pelo Sebrae que está nos auxiliando, além da formalização dos comerciantes junto ao MEI’. Eles terão trinta dias para se adequar as novas regras. (Voz da Bahia, maio, 2017).

O enlace do Programa com a comida de rua, teve como nascedouro a iniciativa pretérita de diagnosticar e regular o comércio, que foi concebida por agentes sociais pertencentes a duas instituições citadinas, o Sindicato de Bares e Restaurantes e a Universidade Federal do Recôncavo da Bahia (UFRB). Ambos contaram com o apoio do Sebrae, como narrou o Gestor do referido serviço, em um dos encontros da pesquisa.

Segundo o Gestor, realizou-se na cidade um levantamento de pesquisa pela universidade, que catalogou e analisou cento e trinta e um empreendimentos de rua. As informações obtidas foram repassadas aos idealizadores do SAJ Legal, que, iniciaram um processo de "capacitação" dos trabalhadores, em parceria entre Prefeitura e Sebrae. Os ambulantes deveriam participar, obrigatoriamente, de, no mínimo, quinze horas de palestras anuais, para adquirir uma certificação do Programa.

Nas palavras do Gestor, "isso foi muito bacana, porque, naquele momento, fortaleceu bastante a relação do Sebrae com esse público e criou um vínculo interessante". Contudo, essa conexão se enfraqueceu, "porque não houve uma obrigatoriedade posterior, nos anos subsequentes, de participar", segundo complementou.

Verifica-se que as falas do Gestor do Sebrae remetem ao entendimento de que o tipo de ação pontual perpetrada não expressava a necessidade daqueles trabalhadores, Macedo (2010) reforça essa informação na assertiva de que estratégias intervencionistas verticalizadas, sustentadas por meio de uma educação disciplinar, não constituem experiências significativas que envolvem os sujeitos, mas sim transmissão de técnicas e a prescrição por si. Nesse âmbito, a resposta dos ambulantes foi apenas o cumprimento das regras impositivas e, tão logo, o abandono do hipotético vínculo estabelecido.

Das ponderações sociais, políticas e institucionais que acercaram o SAJ Legal focalizemos os alvos principais desse processo, os agentes que laboravam no comércio da comida na cidade, ou seja, os ambulantes.

Em termos de caracterização, os ambulantes da comida de rua, podiam ser englobados, em parte, na categoria 
estabelecida por Gurtoo e Williams (2009), ao classificar 'empreendedores da comida de rua' na Índia. Os autores destacaram elementos caraterísticos da simplicidade desses comerciantes, que ocupam um espaço estacionário em algum local público/privado, ou são móveis transportando suas mercadorias em carrinhos, ou cestas em suas cabeças. Entretanto, cabe ressaltar que essa tradução resguarda uma ótica um tanto reducionista, que se apega ao aspecto visual.

Ressalta-se que, embora a legislação nacional defina uma categoria de MEI, ao qual o ambulante 'formalizado' se enquadra, os trabalhadores contextualizados neste estudo, vão homogeneizar-se na acepção que os reúne enquanto parte de um comércio tradicional, conforme a classificação de Antunes (2018).

Ao tratar um esboço acerca da fenomenologia da informalidade no Brasil, o autor enquadra os "vendedores ambulantes de artigos de consumo imediato, como alimentos", no rol dos trabalhadores informais tradicionais. "Inseridos em atividades que requerem baixa capitalização, buscando obter uma renda para consumo individual e familiar [...] que vivem de sua força de trabalho, podendo se utilizar do auxílio de trabalho familiar ou de ajudantes temporários” (Antunes, 2018, p. 68).

Portanto, tomando por base as acepções supracitadas, deve-se ponderar que, para além do conjunto estrutural, vislumbrado por Gurtoo e Williams (2009), se consideradas as atividades implicadas e as interações que esses sujeitos desenvolvem na cotidianidade urbana, com outros entes materiais ou imateriais implicados no seu labor, esse comércio qualificado como "simples" incorpora complexidades de outra ordem.

Nesses remodelamentos as distintas formas de apresentar-se e ocupar a cidade pelos ambulantes de SAJ, demandaram a realização do mapeamento, cadastro e padronização desses trabalhadores, para que se adequassem as novas regras estabelecidas pelo Programa SAJ Legal. Estas implicavam: mudança nos carrinhos (padronização com estrutura em alumínio e cobertura de toldo, já que existiam estruturas de vários tipos de materiais, como bancas de madeira, carrinhos de ferro e/ou alumínio, dos quais muitos não possuíam toldo) e de outras formas de vender comidas nas ruas (como no caso dos trailers).

Incluía-se ainda a uniformização dos vestuários, com escolha e custo da produção de fardas assumidos pelos próprios ambulantes; participação em cursos, que reuniam temas no âmbito da gestão, atendimento ao público, boas práticas e manipulação segura dos alimentos, organizados pelo Sebrae e a Vigilância Sanitária Municipal.

Após o cumprimento dessas etapas e em posse do certificado do curso, os ambulantes que participaram do processo, receberam a nova identidade social e econômica de MEI, por meio do cadastro no Sebrae. Sobre o apoio desta Instituição brasileira na empreitada empreendedora, há de se ponderar um aspecto relevante, que se configura no papel ideológico de instituições públicas como o Sebrae, que para Raslan (2019) promovem a sujeição dos trabalhadores às condições de subordinação, ao fomentar, permanentemente, o discurso do empreendedorismo.

Ao resgatar a definição que a instituição brasileira construiu para harmonizar uma classe ampla de 'donos de negócio', percebe-se que o advento do MEI veio delimitar, horizontalmente, um segmento bastante heterogêneo de trabalhadores. Neste alinhamento, mesmo ambulantes com um simples carrinho de tração manual, a exemplo dos ambulantes de SAJ, que não têm instituída a propriedade do solo que usufruem, vão tornar-se "empresários", tal qual gestores de pequenas empresas que, em oposição, são proprietários do seu terreno/ponto.

Nesses direcionamentos, para o ambulante, tornar-se empreendedor, não concebia as liberdades decisórias típicas de um proprietário do empreendimento, pois elas estavam fortemente condicionadas as autoridades locais. "O direito dos vendedores de rua ao trabalho colide com o reconhecimento, igualmente fundamental, dos espaços públicos, como propriedade de todos e de ninguém, e, portanto, livre de interesses privados" (Marras, 2014, p. 6).

Tal assertiva denota a existência de critérios injustos, no que tange às garantias de direitos e deveres isonômicos, figurando na instabilidade do 'empreendedor' de rua, pois, ainda que cumpra suas obrigações legais, pode ter o negócio removido, apreendido ou suspenso, por ocupar um espaço público. Nessa perspectiva, agrupar distintas atribuições em um rol linear, ainda que resguardando particularidades, requer muitas implicações e análises, para que políticas públicas não resultem 
em intervenções nefastas.

Os representantes do poder público local, cientes de que, para muitos ambulantes conseguirem cumprir as exigências do Programa necessitariam de investimento financeiro significativo, viabilizaram, estrategicamente, a participação de uma entidade financeira, na primeira etapa de aplicação do SAJ Legal, efetivada na Praça. O relato de Marta, vendedora de crepe, explica esse fato:

Botaram um Banco, no dia da reunião na Praça, os funcionários foram conversar com a gente para tomar empréstimo, o Credamigo. Para gente fazer esse empréstimo, para poder, quem não tivesse condições, tomava o empréstimo e fazia o carrinho. Só que eu não sei se alguém fez isso. Acho que não deu para ninguém, porque o Credamigo teria que ser um grupo de cinco e se um não pagasse, os outros teriam que se responsabilizar, não podia atrasar um dia! Ninguém quis! (Marta, agosto, 2018).

A fala remete a atmosfera de pressão que os ambulantes vivenciaram, constrangidos a sucumbir para manter seu meio de sobrevivência. Parte expressiva desses trabalhadores resistiu e buscou meios alternativos de financiar seu 'negócio', contudo, os que não possuíam condições financeiras e não aceitaram o empréstimo, e, portanto, não se adequaram as regras no prazo estipulado, foram cadastrados, mas ficaram excluídos de exercer suas atividades nas circunscrições da Praça.

Respaldados de que as oportunidades foram oferecidas aos vendedores, os entes públicos legitimaram suas ações em SAJ, o Programa obteve êxito em seu propósito ordenador. A região do Centro Comercial experimentara uma espécie de "revitalização", com efetivação da higienização social do espaço público, que incluiu desapropriações e/ou deslocamentos dos agentes habituais para áreas distintas e a modificação estética da localidade.

Os entendimentos expostos coadunam com a visão apregoada por Jessé de Souza, quando analisa que, a ideia de transformar o ambulante em empreendedor fomenta-se no terreno do capitalismo financeiro, "É típico dos interesses dos dominantes pretenderem representar a universalidade, deixando os interesses dos dominados na dimensão do 'particular'. Hoje, só se fala de 'empreendedorismo', como se todos pudessem se tornar empresários” (Souza, 2012, p. 42).

As tecissituras que culminaram na efetivação do SAJ Legal, reverberam, em um contexto singular, a força impetrada pela "engenharia de dominação do capital", aludida por Antunes (2018, p. 266), que se reinventa a cada crise, busca novas formas de requalificar e apreender uma massa de trabalhadores à espreita, mas que constituem força motriz para alimentá-lo economicamente. Por outro lado, a nova ordem a ser instituída na cidade, encontrou resistências, que, embora manifestadas sutilmente, sobreviviam entre astúcias e estratégias dos trabalhadores das ruas.

\subsection{Resistências, dissonâncias, laços frágeis: elementos do vir-a-ser empreendedor na comida de rua}

A implantação do SAJ Legal consistiu em um processo acirrado e mediado por embates políticos e jurídicos, com envolvimento de vereadores, advogados e promotoria, sujeitos que se colocavam a favor ou contrários às manifestações dos ambulantes. Se por um lado, a necessidade de regulamentação ressoava como discurso de ordem e efetivo poder municipal, por outro, as questões inerentes à estrutura social e econômica dos populares, sobretudo, o sustento de uma classe trabalhadora iam de encontro a esses ideais.

O investimento na comida de rua para os ambulantes se dava também por meio de iniciativas pessoais, que conjugavam um esforço premente para encarar os percursos tortuosos das ruas, ao utilizar táticas e astúcias de praticantes, parafraseando De Certeau (2014), para driblar os julgamentos morais e as imprevisibilidades do meio urbano, ou ainda perpetuar uma história de vida familiar no comércio.

Uma das trabalhadoras entrevistadas, cuja família sobrevivia da venda de amendoins cozidos na rua, repercutiu a insatisfação com as imposições do Programa. Essa mulher introduziu para a pesquisa, a denominação de MEI, enquanto categoria do trabalhador da comida de rua em SAJ. 
O Prefeito anterior, já nos tratava como microempreendedores. Eu não! Continuava sendo ambulante! Aí ele queria tirar a gente. Todos! Foi quando esse vereador ajudou a gente, fomos na câmara, ele tomou partido, foi que a gente ficou na rua, por causa disso. Porque o que ele (Prefeito) queria, era limpar a cidade para os turistas (Jane, outubro, 2018).

Jane demonstrava um sentimento de indignação com o novo modo de classificá-los que, na sua ótica, tinha uma conotação negativa, ao significar um meio de desapropriá-los do comércio e limpar a cidade para os "turistas", termo que ela utilizava para designar transeuntes intermunicipais/estaduais, que frequentam a cidade em busca do comércio e serviços. Ao reafirmar-se ambulante, em sua atitude de microresistência, Jane reconhece uma identidade própria de trabalhadora urbana, da qual orgulha-se e não aspira desvencilhar-se, e, ao mesmo tempo, desdenha de maneira passiva, da estratégia uniformizadora do jogo político, que the impunha lugar demarcado.

Percebe-se assim que a identidade do trabalhador, embora parte de uma estrutura capitalista determinista, não se concebe apenas por imposição vertical. Percebe-se uma construção simbólica que permeia os processos de constituição profissional e perpassa o sentimento de inclusão social.

Richard Sennett traz que, no sentido estrito do termo, identidade é uma maneira consciente de formar as regras pelas quais alguém se coloca nos espaços sociais, é precisamente uma identificação de si mesmo na sociedade. $\mathrm{O}$ autor refletiu ainda que, "em regra geral, a identidade não é tanto uma questão do que fazemos, e sim do lugar a que nos integramos" (Sennett, 2006, p. 59).

A manifestação contrária da ambulante encontrou apoio em um representante do poder público e irrompeu uma mobilização de trabalhadores informais, os quais apresentaram uma espécie de resistência velada à sua desapropriação, ao tempo que sucumbiram a categorização de MEI, o que, para boa parte, não implicaria em uma retirada do lugar em que exerciam sua atividade fim. Dissimuladas, as resistências dos ambulantes da Praça se manifestavam nas entrelinhas dos discursos e posturas subjetivadas, ou na atitude naturalizada como característica marcante do seu comércio na comida de rua.

Compunham exemplos de manifestações subversivas verificados: carrinhos estacionados fora do ponto, por proprietários que julgavam terem recebido tratamento desigual na demarcação dos espaços; carrinhos equipados com aparelhos sonoros ligados em volume alto, em desacordo com o parâmetro estabelecido para o local e que despertavam sentimentos de afinidade ou antipatia do público e demais ambulantes; comercialização indevida de bebidas alcoólicas; recusa no uso de fardamentos, verbalizada como 'esquecimento' para os fiscais, mas admitida como proposital, nas alocuções da pesquisa; entre outros aspectos.

Essas atuações revelavam o enfrentamento ideológico e a dificuldade de aceitar a padronização aplicada, características traduzidas aqui no "vir-a-ser empreendedor", enquanto um processo tenso, que convergia e divergia entre ambulantes. Assim, nas conformações dos sentidos, mediante a categorização estabelecida, as significações atribuídas por comerciantes "antigos" e "novos", para essa intervenção municipal, eram dissonantes.

Convém demarcar, primeiramente, que essa forma de hierarquizar os trabalhadores como "antigos" e "novos" foi definida pelos próprios ambulantes. Eles denominavam "antigos" os grupos familiares de trabalhadores que já estavam alocados na Praça, anteriormente ao SAJ Legal, de tal modo, os que se instalaram com o advento do Programa eram considerados novos.

Os antigos comerciantes galgaram historicamente um lugar na Praça, lugar, cuja obtenção resultou por meio de um processo dispendioso, em termos de conquista do espaço e uma "batalha" árdua de trabalho, que se perpetuava na herança familiar dos pontos. Esse pertencimento ao lugar, ao que parece, foi desvencilhado e obscurecido na implantação do SAJ Legal.

Portanto, os trabalhadores antigos percebiam os novos comerciantes como mais beneficiados pelo Programa, devido a 
sua rápida e 'facilitada' inserção na Praça, que, para eles, estava atrelada a uma maior disponibilidade financeira, que os novatos possuíam. De fato, isso propiciou um ingresso célere e a tomada de pontos estratégicos de venda pelos novos ingressos, por se estruturarem antes do vencimento do prazo previsto.

Nessa disposição horizontal, subjaz um remodelamento estratificatório dos trabalhadores ambulantes, que se apresentavam sob distintas camadas econômico-sociais. Todavia, alinhavam-se em condições de gênero e etnia, visto que a maioria das famílias era constituída por mulheres e negros. Entre "novatos" estavam trabalhadores que acumulavam melhores condições de renda, por possuírem outros meios alternativos de subsistência e usufruírem de uma situação relativamente confortável, mediante os demais.

Nessas circunscrições nota-se, sobretudo, que embora estes grupos de antigos e novos ambulantes, tenham perseguido trilhas distintas para ocupar a Praça, o modelo do comércio familiar como herança na comida de rua conformava um construto estrutural demarcado, que se replicava mesmo entre os novatos. No Brasil, a agricultura familiar nos remete um exemplo popularizado deste movimento, muito embora fragilizado. Como demonstraram Costa \& Rocha (2020, p. 8), nesse ramo, à "sucessão profissional é mediada pela passagem da gerência do negócio, do poder e da capacidade de utilização do patrimônio na próxima geração".

Portanto, a comida de rua vai resguardar similitudes dessa rede familiar implicada aos pequenos agricultores, pelos aspectos de passagem do negócio e dos ativos possuídos, adicionando-lhes os saberes incorporados ao fazer culinário. Bem assim, embora universos dissonantes, respectivamente, da esfera do direito privado e do espaço público, as fragilidades implicadas na agricultura familiar, em sua histórica luta pelos direitos de propriedade da terra, nos remetem a reflexão acerca do não direito ao ponto, duramente conquistado pela maioria dos ambulantes na comida de rua.

O SAJ Legal expôs essa contradição, na qual, aos ambulantes instituídos dos deveres de MEI, restava apenas agarrarse à construção cultural e histórica, amoldada nas relações com a clientela, transeuntes e outros comerciantes, para adquirir um lugar simbólico, traduzido como o ponto tradicionalmente apropriado pela família no perímetro urbano.

Esse modelo de sucessão hereditária é bem complexo e subjaz intrincado ao próprio sistema capitalista, como evidenciado em Engels (1984, p. 3) "nessa estrutura da sociedade baseada em laços de parentesco, a produtividade do trabalho aumenta sem cessar, e, com ela desenvolvem-se a sociedade privada e as trocas, as diferenças de riqueza, a capacidade de empregar força de trabalho alheia e com isso a base dos antagonismos de classe."

Nesse ínterim, percebia-se que os novos MEI da comida de rua em SAJ eram os principais agenciadores de terceiros, familiares ou empregados, que se reuniam em uma condição de subemprego autorizada, visto que os vínculos empregatícios, constituíam laços frágeis, devido à ausência de relações trabalhistas formais, que a própria regulação empreendedora nacional fomentava. Se a labuta com a comida de rua era árdua, para quem se declarava empreendedor, mais oneroso ainda o era, para aqueles que processavam as atividades ordinárias desse fazer, sem perspectivas de um ganho justo.

Observa-se que as formas de precarização, que a ideologia empreendedora "regulariza" nos ambientes da comida de rua, contribuem para desqualificar e ampliar as formas de subsunção no trabalho, multiplicando mecanismos de auto exploração, além de compor um terceiro exército de trabalhadores, que Antunes (2018) aludiu como "informais instáveis", superexplorados e desprovidos de quaisquer direitos sociais, ou trabalhistas.

Esses "trabalhadores informais instáveis", que realizam trabalhos eventuais e contingenciais, absorvidos pelas formas de trabalho precário, vivem em uma situação que oscila de provisória, para permanente. São subempregados, de uma categoria menos instável, "os quais possuem um mínimo de conhecimento profissional e os meios de trabalho", possibilitando contratálos (Antunes, 2018, p. 69).

Rosa representava uma dessas trabalhadoras, que ingressara no ramo da comida de rua por meio de uma microempreendedora novata. Na sua curta experiência de trabalho, Rosa abandonou a "função" de doméstica que, como 
analisa Da Matta (1986), mas se classifica como um "serviço" na ótica brasileira; para galgar um lugar de pertencimento na comida de rua. Empregando-se nesse comércio, que faz das ruas um domínio de "batente", trabalhava cerca de quinze horas/dia, enfrentava desafios e construía planos para ultrapassar o papel de empregada e um dia, quem sabe, chegar à posição de empreendedora, abrindo seu próprio negócio.

Castro (2019) argumenta que, atualmente, se exige do cidadão um desempenho heroico no trabalho, em que atinja, por seu próprio mérito, um nível de individualidade passando a ação, ou seja, uma espécie de singularização, por meio da qual é possível se construir uma identidade. A consequência disso é que "o ponto de vista do ator domina, a mitologia da autorrealização: cada um deve aprender a se governar por si mesmo e encontrar as orientações para sua existência em si mesmo" (Castro, 2019, p. 151).

Essa mitologia encontra sua forma dominante, na figura e nos modos de ação do empreendedor e nos modos da ação empreendedora. Ela ganha espaço na esfera da vida no trabalho, porque, em um mundo em que o Estado perdeu o papel de garantidor das mínimas condições de vida e, em que, a crença na política como instrumento de transformação perdeu espaço, há que se buscar salvação em si mesmo (Castro, 2019).

O desejo de Rosa revelava que o comércio de rua, podia ser compreendido a partir de posturas divergentes, se por um lado aparecia como vínculo informal e precário, diante de uma sociedade vista como "desenvolvida", por outro, despontava como meta profissional para aqueles que desejavam 'empreender', sem a necessidade de esquivar-se a uma educação formal para adquirir uma cobiçada liberdade financeira.

Nesses direcionamentos, a marca desse "empreendedorismo", que avança na classe proletária brasileira, exprime um regime de super exploração, cuja meta maior é uma apropriação do negócio, um sonho capital. Essa aspiração parece traduzirse na passagem para um regime de auto exploração, em que a obtenção de ganhos financeiros, depende da manutenção de uma força de trabalho perene, que desdenha de outros aspectos significantes da vida, como a convivência familiar e a saúde.

Ao analisar os fazeres envoltos nessa atividade ambulante em SAJ, Santana e Amparo-Santos (2021, p. 6), revelaram que "do preparo à venda da comida, a rotina diária de afazeres perfazia, em média, um período de doze horas, para a maioria dos ambulantes, repetindo-se ou intensificando-se aos finais de semana e feriados. Essa atividade contínua implicava em uma negação sobre o tempo de lazer e de convivência social, bem como um cuidado restrito com a saúde".

Oposta à condição de Rosa, encontrava-se Marta, a microempreendedora que a contratou, ela possuía um carrinho de crepe e se enquadrava nos moldes constituídos pelo Programa, mantinha fardamento e obrigações legais em dia e sempre trazia relatos positivos sobre como tudo foi organizado pela Prefeitura.

Suas atitudes coadunavam com a do empreendedor teorizado pelo Sebrae: contratação de funcionários, melhorias no carrinho e metas para ampliação do negócio, fardamento impecável e aplicação das técnicas de atendimento ao público, apreendidas nas capacitações. Entretanto, por ser oriunda do mercado formal, via a experiência de adentrar a comida de rua como transitória:

Não penso em ficar por muito tempo. Porque como você está acostumado a sair de manhã, a trabalhar o dia todo - a trabalhar! E chega aqui fica sentado esperando, é difícil. Falar a verdade, não gostei dessa experiência. Para quem não trabalha, não tem nada, não fica sem dinheiro, mas se eu tivesse outra coisa [...] (Marta, setembro, 2018).

Na sua fala era premente o descontentamento com o comércio, todavia, na prática, o sentimento ficava invisibilizado pelo seu modo de agir 'profissional', ao desempenhar atividades com afinco, destreza e bom humor. Irene Tinker revelou, em seu estudo realizado na Nigéria, que o sentimento expresso por Marta, já fora partilhado por distintos cidadãos, ao descrever que os ambulantes da comida de rua "veem seus empreendimentos como parte das estratégias de sobrevivência da família" (Tinker, 1997, p. 208). 
Por outro lado, para Marta, não era o fato de lidar com a comida, mas estar no ambiente da rua e exercer a paciência demandada por esse comércio, que a desagradavam. Por isso, constantemente, verbalizava o desejo de possuir um comércio fixo, uma creperia, na qual pudesse exercer suas atividades em conformidade aos aprendizados adquiridos no curso de culinária que frequentou. Enquanto Marta contornava o fato de ser comerciante de rua, orgulhando-se da moderna condição de MEI, Jane, veterana na Praça, glorificava o fato de ser ambulante, identidade que lhe acompanhava por gerações.

Após trabalhar com sua mãe, desde criança, na venda do acarajé, Jane experimentou outras ocupações, como diarista, vendedora de roupas em feiras livres e um emprego numa fábrica de fogos clandestina instalada na periferia de SAJ. Emprego que, segundo a historieta que partilhou com a pesquisadora, intuitivamente abandonou, antes da tragédia da explosão na fábrica, evento noticiado pela mídia nacional e internacional, que cerceou várias vidas e demarcou com sequelas outras, inclusive de familiares seus, que reorientou seu retorno à comida de rua.

A venda de amendoins simbolizava uma luta digna, meio de sobrevivência para sua família, por mais de duas décadas. Segundo comentava, o "emprego estava difícil, para quem não tinha educação formal, até mesmo para quem tinha", assim sendo, restou-lhe seguir a vocação familiar. Entretanto, tornar-se MEI significou uma intervenção financeiramente honerosa para Jane, que precisou arcar para adquirir o direito de permanecer na Praça.

Raul, também comerciante de amendoim cozido, atravessou processo semelhante, após um acidente vascular cerebral, que lhe deixou sequelas, passou a sustentar a família e propiciou a obtenção de diploma de nível superior aos três filhos, perseverando na ocupação de ambulante. Com a implantação do SAJ Legal e a extinção da venda de bebidas alcoólicas na Praça, um complemento de renda importante para ele, ficou transtornado e verbalizava essa insatisfação cotidianamente, inclusive com a condição de MEI.

$\mathrm{Na}$ impositiva pessoal de permanecer na Praça ajustou o carrinho às condições regulamentares, contratou uma senhora para ajudá-lo, mas não se curvava perante as exigências do Programa, como uso de fardamento, que via como detalhe. A fiscalização não representava um impeditivo para suas resistências, exibia-lhes o Alvará, que justificava o pagamento do imposto em dia, como se o instrumento o isentasse de outras obrigações, que julgava desnecessárias.

Na dialética capitalista, Jane e Raul podiam ser concorrentes, pois comercializavam a mesma comida e disputavam clientes, contudo, naquelas imediações, o fato de compartilharem uma identidade social de ambulante, os unia. Embora a hierarquia existente entre novos e antigos ambulantes se conformasse nas suas qualificações narrativas, os trabalhadores da comida na Praça conformavam uma rede de apoio, fortalecida pela luta em comum, do direito de comercializar nas ruas.

No decorrer da estadia em campo, as vivências e situações comunicativas partilhadas entre ambulantes, fizeram compreender que, incorporada na essência da trajetória profissional de cada um e nas similares lutas cotidianas, a conformação do empreendedor se consolidava. Isso porque, para lograrem às ruas, esses sujeitos vivenciaram histórias de batalha, perdas e conquistas, que resultaram na reafirmação do seu comércio, em meio a urbe, alcançando, um lugar instável, mas que lhes propiciava sobrevivência e ocupação digna.

Dessa forma, atribuir-lhes o desígnio social de microempreendedor, regular a atividade, reconhecer seu papel cultural e econômico no panorama social, parecia justo. Contudo, forçá-los a uma identificação vertical, ausente um planejamento coletivo e alheios a oferta de condições equânimes, em um curto prazo, ressoou como uma intervenção oportuna para uns e nefasta para outros.

Diante dessas elucubrações, argumenta-se que, ao ingressar o comércio da comida de rua, essa tática empreendedora ressoou, principalmente, como uma política de governança embasada em um discurso neoliberal. Esta política, alinha interesses do poder público e entes privados, na perspectiva de amoldar "pacificamente" trabalhadores, imputando-lhes um lugar simbólico, na sociedade do reconhecimento e no comércio regulamentado.

Ademais, congrega fatores físicos, como a fusão de novos equipamentos estruturantes, para uso nas ruas e toca 
valores subjetivos dos sujeitos implicados, com intervenções que contribuem para disseminar a ideia de que, ao tornar-se empreendedor, adquire-se status econômico, que pode acarretar na passagem do obscurantismo social, para ingressar o glamour cultural de uma experiência alinhada aos ideais modernistas da expressão citadina.

A noção do empreender demonstrada, revela que, para além da estratégia qualificadora do MEI assumida pelo SAJ Legal e da lógica imposta, estavam intrincadas no comércio características individuais. Essas agregavam traços coletivos, como a determinação e o enfrentamento para instituir "carreira", em termos ideológicos e morais, diante das pressões do cenário urbano e dos estereótipos atribuídos aos ambulantes. Estas são contradições nas quais residem o lugar do vir-a-ser empreendedor na comida de rua.

\section{Considerações Finais}

Ambulantes ou microempreendedores, quaisquer que sejam as nomenclaturas, não descartam a essência constitutiva de trabalhadores. Uma identidade social manchada pela alcunha pejorativa da informalidade, condição que minimiza a herança sócio histórica e econômica desses comerciantes, relegados a marginalização e a desproteção social, durante séculos.

As alocuções dos ambulantes na pesquisa revelaram que a qualificação e o reconhecimento de seus comércios e empreitadas, como resultado de um processo empreendedor, condizia com seus feitos e trajetórias. Contudo, o modus operandi procedido pelo SAJ Legal para classificá-los, contrariou expectativas, sendo frequentemente enfrentado por atuações, que se conjugavam nas tecissituras de uma rede de resistências e dissonâncias.

A regulamentação como MEI repercutiu negativamente para os ambulantes, que se viram compelidos a mais deveres que direitos, fatores que implicaram em uma maior segregação do comércio, instabilidade financeira das famílias, com aumento da vulnerabilidade social, entre subempregados e desalojados da Praça. Nessa condição, formalizar o trabalhador da comida de rua como MEI, sem promover intervenções de cunho sócio estruturais que implicassem na real evolução das condições de trabalho dos envolvidos, representou menos uma política resolutiva para o comércio e ambulantes, que se adequaram a ela, do que repercutiu como parâmetro de higienização social e estratégia econômica.

Essas manifestações denotam que a corrosão dos direitos do trabalhador, encoberta sob o véu do discurso empresarial e neoliberal, atendem, prioritariamente, ao mercado financeiro e representam o contingenciamento de novas formas de exclusão e precarização dos vínculos de trabalho. No caso dos ambulantes de SAJ, ao invés de conduzi-los para uma política de proteção social, atribui-lhes uma série de obrigações e imposições, que culminaram na extinção de meios de sobrevivência, ou na resistência passiva a essas formas de dominação.

Assim, as discussões fomentadas no presente artigo desvelam argumentos que vão demonstrar que, a categorização de empreendedor na comida de rua brasileira, parece conformar uma tentativa de reconfiguração desse comércio. Essa reformatação se estabelece por meio da propagação política de uma ideologia meritocrática e regulatória de cunho neoliberal, que subjaz ao próprio sistema capitalista, sendo imposta ao ambulante da comida de rua ao experimentar uma nova identidade de MEI, que na prática se conforma enquanto um vir-a-ser empreendedor.

É nesse sentido que a análise do microcosmo social em SAJ pretendeu despertar reflexões e fornecer pistas, para compreensão e delineamento de políticas públicas viáveis, direcionadas ao comércio informal, que se apresentem em consonância com as necessidades contextuais e incluam a participação popular no processo.

Para isso, sugere-se a proposição de novos estudos, que contemplem o universo laboral dos ambulantes, nos distintos territórios em que se apresentam, com vistas a compreender como se processam as práticas em torno da produção da comida para comercialização nas ruas. No entendimento de que tais práticas, embora permeadas por questões de Saúde Pública, muitas vezes excluem do rol de Políticas da Saúde, os ambulantes e suas famílias. 


\section{Agradecimentos}

A Fundação de Amparo à Pesquisa do Estado da Bahia (FAPESB), pelo apoio financeiro à capacitação da autora principal, em nível de doutoramento.

\section{Referências}

Anjaria, J. S. (2016). The Slow Boil. Street Food, Rights, Space Public in Mumbai. Stanford University.

Antunes, R. (2019). Riqueza e miséria do trabalho no Brasil IV: Trabalho digital, autogestão e expropriação da vida: o mosaico da exploração. São Paulo: Boitempo.

Antunes, R. (2018). O privilégio da servidão: o novo proletariado de serviços na era digital. Boitempo.

Baron, R., \& Shane, S. A. (2007). Empreendedorismo: uma visão do processo. Thompson.

Bhowmick, S. K. (2010). Street vendors in the global urban economyRoutledge. Taylor \& Francis Group.

Bitter, D., \& Bitar, N. P. (2012). Comida, trabalho e patrimônio. Notas sobre o ofício das baianas de acarajé e das tacacazeiras. Horizontes Antropológicos, 18(38): 213-236.

Bourdieu, P. (2012). A miséria do mundo. Vozes.

Castro, B. (2019). Quando gênero revela classe: mulheres e flexibilidade no setor da tecnologia da informação. In: ANTUNES, R. (org.) Riqueza e miséria do trabalho no Brasil IV: Trabalho digital, autogestão e expropriação da vida: O mosaico da exploração. (pp. 145-163), São Paulo: Boitempo.

Chen, M. A. (2012). The Informal Economy: Definitions, theories and policies. Wiego Work Paper, 1.

Costa, M. C. L., \& Rocha, C. G. S. (2020). Sucessão hereditária na agricultura familiar: estudo de caso dos agricultores da Vicinal 12, Brasil Novo, Pará. Research, Society and Development, 9(7): 1-18. http://dx.doi.org/10.33448/rsd-v9i7.3908.

Da Matta, R. (1986). O que faz do brasil, Brasil? Rocco.

De Certeau, M. (2014). A invenção do cotidiano 1. Artes de fazer: Vozes.

Durães, B. J. R. (2002). Trabalho Informal: Um paralelo entre os trabalhadores de rua da cidade de Salvador no século XIX e no século XXI. Caderno CRH, 37, 289-308.

Engels, F. (1984). A origem da família, da propriedade privada e do estado. (9a ed.), Civilização Brasileira.

Etzold, B. (2014). Towards fair street food governance in Dakha: moving from exploitation and eviction to social recognition and support. In: CARDOSO, R. C. V. et al. Street food. Culture, Economy, Healthy and Governance. (pp. 61-82), Routledge.

Ferreira-Filho. A. H. (1998-1999). Desafricanizar as ruas: elites letradas, mulheres pobres e cultura popular em Salvador (1890-1937). Revista Afro-Ásia, 21$22,239-256$.

Greenspan, A. (2018). Moveable feasts: reflections on Shanghai’s street food. Food, Culture \& Society, 21(1): 75-88.

Geertz, C. (2008). A interpretação das culturas. LTC.

Gurtoo, A., \& Williams, C. C. (2009). Empreendedorismo e setor informal: algumas lições da Índia. Internacional Journal of Entrepreneurship and Innovation, 10(1): 55-62.

Instituto Brasileiro de Geografia e Estatística. (2018). Estimativas da população residente nos municípios brasileiros. Diretoria de Pesquisas. https://agenciadenoticias.ibge.gov.br/agencia-deta lhe-demidia.html?view=mediaibge\&catid=2103\&id=227 9.htm.

Isaacs B. (2014). "The tastiest food is in the small streets. The politics of flavor and nostalgia in Bangkok". In: Cardoso, R. C. V. et al. Street food. Culture, Economy, Healthy and Governance. (pp. 195-213), Routledge.

Kaufmann, J. C. (2018). A entrevista compreensiva: um guia para pesquisa de campo. Vozes.

Macedo, R. S. (2010). Compreender/mediar a formação o fundante da educação. Liber Livro.

Maia, A. C. N. (2015). Redes do comércio de rua de Salvador, Bahia. Mercator, 14(2): 45-56.

Marras, S. (2014). Comparative analysis of legislative approaches to street food in South American metropolises. In: Cardoso, R. C. V. et al. Street food. Culture, Economy, healthy and Governance. (pp. 15-45), Routledge.

Martin, N. (2014). Food fight! Immigrant Street Vendors, Gourmet Food Trucks and the Differential Valuation of Creative Producers in Chicago. International Journal of Urban and Regional Research, 38(5): 1867-1883.

Matzembacher, et al. (2019). Can street entrepreneurs be Schumpeterian entrepreneurs? The case of food trucks as family firms in an emerging country. Journal of Global Entrepreneurship Research, 9(6): 1-24. 
Research, Society and Development, v. 10, n. 3, e30110313497, 2021

(CC BY 4.0) | ISSN 2525-3409 | DOI: http://dx.doi.org/10.33448/rsd-v10i3.13497

Naik, A. (2013). Contextualising Urban Livelihoods: Street Vending in India. SSRN Electronic Journal. Recuperado de https://papers.ssrn.com /sol3/papers.cfm?abstract_id=2238589.htm.

Paula JR. J. V. (2005). Discursos libertários: entre a “inclusão" e “um Novo mundo possível”. Revista de Ciências Sociais, 23, 49-64.

Pereira, A. S. et al. (2018). Metodologia do trabalho científico. UFSM. https://repositorio.ufsm.br/bitstream/ handle/1/15824/Lic_Computacao_MetodologiaPesquisa-Cientifica.pdf?sequence=1\&isAllowed=y

Portal Sebrae (2019). Perfil do microempreendedor individual. https://m.sebrae.com.br/sites/PortalSebrae/estudos_pesquisas/ estudosapresentamperfildomicroempreendedorindividualdetalhe.htm.

Raslan, F. O. Sapataria Pandora: Informalidade e desenvolvimento da indústria de calçados de Nova Serrana (MG). In: Antunes, R. (org.) Riqueza e miséria do trabalho no Brasil IV: Trabalho digital, autogestão e expropriação da vida: O mosaico da exploração. (pp. 145-163), Boitempo.

Santana, G. R. \& Amparo-Santos, L. (2021). Da promoção da SAN à invisibilidade social: O trabalho dos artífices ambulantes na comida de rua no Brasil. Research, Society and Development, 10(2): 1-13. http://dx.doi.org/10.33448/rsd-v10i2.12862.

Santana, G. R. \& Amparo-Santos, L. (2019). Institutionalization of Street Food in the Modern Urban Space: Conformations, Tensions and Conflicts. Journal of Food and Nutrition Research, 7(6): 465-475. 10.12691/jfnr-7-6-9.

Sennett, R. (2006). A cultura do novo capitalismo. Record.

Solomon, H. (2015). "The taste no chef can give”: Processing Street Food in Mumbai. Cultural Anthropology, 30(1): 65-90.

Souza, J. (2012). Os batalhadores brasileiros: nova classe média ou nova classe trabalhadora? UFMG.

Tarulevicz, N. (2018). Hawkerpreneurs: vendedores ambulantes, empreendedorismo e reinvenção da comida de rua em Singapura. RAE - Revista de Administração de Empresas. São Paulo, 58(3): 291-302.

Tinker, I. (1997). Street Foods: Urban Food and Employment in Developing Countries. Oxford University Press.

Voz da Bahia. SAJ Legal: Carrinhos dos vendedores ambulantes passam por vistorias. <http://www.vozdabahia.com.br/index/blog/id270354/saj_legal_carrinhos_dos_vendedores_ambulantes_passam_por_vistorias.htm.

Winarno, F. G. \& Alain, A. (1986). Street foods in Asia. A proceeding of the Regional Workshop. In: Jogjakarta: FAO and Food Technology Developement Centre. http://www.fao.org/3/U3550t/u3550t08.htm. 